\title{
Role of School Health Officers in Mental Health Care for Secondary School Students in Can Tho City, Vietnam
}

\author{
Dat Tan Nguyen $^{1,2}$ - E. Pamela Wright ${ }^{3} \cdot$ Tam Thi Pham $^{1} \cdot$ Joske Bunders $^{2}$
}

Published online: 1 August 2020

(c) The Author(s) 2020

\begin{abstract}
The objectives of the study were to explore the experiences of school health officers in identifying and managing mental health problems of secondary school students and to gather recommendations from the school officers for improving the effectiveness of mental health care in secondary schools in Can Tho City, Vietnam. We conducted a qualitative study based on in-depth interviews using a semi-structured guideline with 15 school health officers at 15 secondary schools in Can Tho City, Vietnam. Data were analyzed using content-driven analysis to identify recurring themes. The school health officers reported that stress, depression, suicidal ideation, and sexual orientation issues were the most commonly encountered mental health problems among their students. The officers worked with a limited range of interventions for helping these students, such as giving non-narcotic analgesics or advising students to take a short break at school or to go home. Most of them felt that their training was insufficient to deal with mental health problems in an optimal way. They recommended further training to improve their knowledge and skills in recognizing and managing mental health problems in students. They also considered a university-sponsored mental health website a good source of information on mental health care for students. School health officers reported that they did not feel well equipped to manage mental health problems because of insufficient training, lack confidence, and absence of an appropriate network for advice and referral. Updated policies and programs are needed for initial training and refresher courses, which will strengthen the role of school health officers as first line support for secondary school students with mental health problems.
\end{abstract}

Keywords Mental health care $\cdot$ Students $\cdot$ School nurse $\cdot$ School health officers $\cdot$ Vietnam

Dat Tan Nguyen

ntdat@ctump.edu.vn

E. Pamela Wright

pamelagihc@gmail.com

Tam Thi Pham

pttam@ctump.edu.vn

Joske Bunders

j.g.f.bunders-aelen@vu.nl

1 School of Public Health, Can Tho University of Medicine and Pharmacy, No. 179, Nguyen Van Cu Street, An Khanh Ward, Ninh Kieu District, Can Tho City 94117, Vietnam

2 Athena Institute for Research on Innovation and Communication, Faculty of Earth and Life Sciences, Vrije Universiteit Amsterdam, De Boelelaan 1089a, 1081 HV Amsterdam, The Netherlands

3 Guelph International Health Consulting, Frederik Hendrikstraat 18, 1052HT Amsterdam, The Netherlands

\section{Background}

In many countries, the school nurse is the first person a secondary school student will contact in case of a health problem (Fazel, Hoagwood, Stephan, \& Ford, 2014; Fazel, Patel, Thomas, \& Tol, 2014). Typically, school nurses are trained to identify basic health conditions and illnesses and to gauge their severity. In most circumstances, they are able to advise students correctly. However, at present, mental health problems among students appear to be on the rise around the world-from stress and anxiety to depression and suicide (Daya \& Karthikeyan, 2018; Kumar \& Akoijam, 2017; World Health Organization, 2012, 2018). Several reports have demonstrated that school nurses often do not feel well equipped to provide the support that students with mental health problems may need (Greytak et al., 2019; Rosvall \& Nilsson, 2016). School programs aimed at preventing or reducing mental health problems require active 
participation by the school nurse, who must be prepared for that role (Rosvall \& Nilsson, 2016).

In Vietnam, school nurses often do not have a nursing background, and their title is "school health officer." Government regulations require school health officers to have at least a 2 year or 3 year college degree, but they do not need a university degree in medicine or nursing (Ministry of Health and Ministry of Education and Training, 2016). There is no special training program for school health officers. Most are general assistant physicians, with a 3-year diploma at the college level; their work mainly involves providing first aid in case of injuries and taking measures to prevent disease outbreaks in schools. A school health officer is positioned to advise the Administration Board of the school and to carry out health checks on height, weight, blood pressure, heart rate, and eyesight for students at the beginning of the school year. They also are tasked with observing and counseling students and their parents on the general health status including the mental health of students during the school year. However, mental health care is not yet included in the detailed list of healthcare communication and campaigns to be implemented in schools. (Ministry of Health and Ministry of Education and Training, 2016). Mental health is mentioned in the Joint Circular 13/2016/TTLT-BYT-BGDDT on Regulations on Healthcare Activities in Schools issued on May 12, 2016 by the Ministry of Health and Ministry of Education and Training, stating that school health officers are required to take part in workshops, trainings, higher education and professional development opportunities, but there is no mention of how to assist school health officers to participate in those trainings nor any detailed annual plan on such continuous professional development opportunities. As noted in recent systematic reviews, there is a need for much more information about school health, especially about mental health, in low- and middle-income countries (Arenson, Hudson, Lee, \& Lai, 2019; Fazel, Patel, et al., 2014). This is the case in Vietnam, where the mental health of adolescents falls within the remit of the Ministry of Health, the Ministry of Labour, Invalids and Social Affairs and the Ministry of Education and Training, but there are limitations in coordination considered to be led by the Ministry of Health (Overseas Development Institute and UNICEF Vietnam, 2018). In addition, there are no legal documents that mention a role for other school personnel and no requirement for training or a background in mental health for other school personnel to participate in the response to mental health issues in students.

Students in secondary schools in Vietnam are under great pressure to achieve academic success, which can lead to mental health problems and even suicide. Securing a place in a public university is a major step toward a success in later life. Can Tho City is a major urban center in the Mekong Delta, Southern Vietnam, that had approximately 26,000 students distributed across 27 secondary schools in the school year 2013 to 2014 . We have previously reported that more than a quarter of secondary school students surveyed in Can Tho City had suicidal thoughts and more than $10 \%$ had suicidal plans (D. T. Nguyen, Dedding, Pham, Wright, $\&$ Bunders, 2013). The numbers were lower, but still high, in Ho Chi Minh City and Hanoi (Harpham \& Tran, 2006; B. P. Tran, 2007). The main factors related to this problem were high academic pressure, both at home and at school (D. T. Nguyen, Dedding, Pham, \& Bunders, 2013; D. T. Nguyen, Dedding, Pham, Wright, et al., 2013); and emotional and physical abuse by parents or other adults in the household, or by teachers or other staff at school (M. T. Le, Holton, Nguyen, Wolfe, \& Fisher, 2016; D. T. Nguyen, Dedding, Pham, \& Bunders, 2013; D. T. Nguyen, Dedding, Pham, Wright, et al., 2013; T. H. Nguyen, Dunne, \& Le, 2010; Q. A. Tran, Dunne, Vo, \& Luu, 2015). Attitudes and beliefs on mental health are affected by a combination of little knowledge and a mix of traditional and modern views (van der Ham, Wright, Van, Doan, \& Broerse, 2011). Stigma related to mental health is highly prevalent in Vietnam (Do, Pham, Wallick, \& Nastasi, 2014; Vuong, Van Ginneken, Morris, Ha, \& Busse, 2011). It is reported that mental illness is seen as a disgrace, bringing stigma to the whole family; the family will be viewed as bad and as one that has not followed a virtuous path (X. C. Nguyen, 2012). It is said that "whenever people think about mental illness, they will certainly think about madness and strange behavior' (Hong Minh, 2008; Vuong et al., 2011).

Despite growing concerns about the mental health of school students, both financial and human resources to address mental health issues are limited in Vietnam (Niemi, Thanh, Tuan, \& Falkenberg, 2010; Vuong et al., 2011). While it is the responsibility of the school structure as a whole, including parents and teachers, to help students cope with these pressures, a large part of the immediate burden falls upon the health officers, who have daily contact with the students (Daya \& Karthikeyan, 2018; Garmy, Berg, \& Clausson, 2015; D. T. Nguyen, Dedding, Pham, \& Bunders, 2013; D. T. Nguyen, Dedding, Pham, Wright, et al., 2013; Paschall \& Bersamin, 2018; Werner-Seidler, Perry, Calear, Newby, \& Christensen, 2017).

The Vietnamese government has made significant efforts over the last 10 years to develop a policy framework to improve general school health services, such as Directive No. 23/2006/CT-TTg on having well-equipped and professionally qualified health officers in schools (Prime Minister of Vietnam, 2006), and Decision No. 401/2009/QD-TTg, which approved the program "Preventing and combating diseases in educational establishments belonging to the national education system" (Prime Minister of Vietnam, 2009). However, these policies focused on issues such as first aid for injured students and prevention of disease outbreaks in 
schools. Health care related to psychological disorders has not received adequate consideration (Communist Party of Vietnam, 2017). Finding out more about how first line health workers and school health officers perceive and deal with mental health problems among students could reveal gaps that need to be addressed to better serve the large numbers of youth attending secondary schools; such information is not yet available in Vietnam.

In this study, our objectives were to explore the experiences of school health officers in identifying and managing mental health problems of secondary school students and to gather recommendations from the school officers for improving the effectiveness of mental health care in secondary schools in Can Tho City, Vietnam. We investigated how school health officers dealt with mental health problems among students, how they felt about their capacity to cope with these issues, and what they needed to better perform their role in supporting students' mental health.

\section{Methods}

\section{Study Design and Population}

A qualitative research study was conducted with school health officers from November to December, 2015. The health officers were recruited purposively from both public and private secondary schools in nine districts of Can Tho City. The average student population of the schools was 1000 , ranging from 300 to 3000 , and students were between 12 and 20 years of age. The proportions of male and female students were similar in all schools, at approximately 50\% each. Interviews took place privately in the health officers' designated rooms in the schools.

Of the 27 schools invited to join the study, 15 participated but saturation of types of responses with this group of health officers was reached. Most schools had one health officer. Two of the schools had two health officers, but in each case one of them had only a few months of working experience, so these were not included in the study. Of the 12 schools that did not participate, two did not have a health officer, two refused to participate, and the other eight health officers were not available during the period of the study. The 15 health officers participating in the study lived in the local area in Can Tho City.

\section{Data Instruments and Collection}

Data were collected in one-on-one interviews with health officers, using a guide that included semi-structured as well as open-ended questions. To investigate the experiences of school health officers in identifying and managing mental health problems of secondary school students and obtain recommendations from the school officers for improving the effectiveness of mental health care, the interview guide was developed by the research team based on three primary objectives: (1) to identify common mental health problems arising among secondary school students; (2) to describe the activities of school health officers, especially as related to mental health care for students; and (3) to identify health officers' perspectives on potential approaches and activities to improve mental health care in the schools. The interviews followed the structure of the questionnaire, starting with background information about the health officer and continuing through the three objectives. All interviews were conducted in the Vietnamese language by the principle researcher, supported by two final-year students in preventive medicine. The interviews lasted 30-60 min and were audio-recorded. After transcription by the two preventive medicine students, they were translated into English by the principle researcher who reviewed and analyzed them with another member of the research team (PW) who is a native English speaker with adequate proficiency in Vietnamese.

\section{Data Analysis}

The English versions of the interviews were used for analysis, while the original Vietnamese versions and recordings served as a backup. Qualitative content analysis and concept-driven coding were used. The main variables based on the objectives were as follows: common mental health problems; challenges for the health officers; and proposed improvements to mental health care for high school students. The transcripts were read and re-read, first independently and then together by two of the researchers (NTD and PW). First of all, they were screened for words and phrases that could be grouped by similarities and used to establish initial subgroups with repeated concepts and themes that were associated with the selected variables. Secondly, axial coding involved refining this list by deleting or combining categories, followed by making connections between the categories and defining properties, for instance, context or preconditions. Finally, selective coding involved the identification of core categories. In addition, the links between subgroups were identified and the main themes formulated from recurring texts. In the last stage, selective coding led to identification of the key themes that are described in the results. Quotes from the respondents are used to illustrate the points that arose from the analysis.

\section{Website for Mental Health Information}

As part of our larger research program, we also explored the possibility of reducing mental health problems by providing information about health and mental health to students online. There was no existing website with a focus 
on providing mental health information aimed at that age group in Can Tho City, so we designed such a website, with consideration for the characteristics of teenagers and adolescents. The suckhoetre.vn (youth health) website has three main sections, providing students with information on health and on skills, and a health checkup. It was launched for public use in 2016, with the aim of meeting the needs of secondary school students for information on mental health and psychological wellbeing in Can Tho City. The sources of information are from official websites on mental health in both national and international levels such as kidshealth. org, youngminds.org.uk. Information is also collected and edited by the admin group from Can Tho University of Medicine and Pharmacy. A description of the structure, design and assessment on the application of the website has been presented elsewhere (Dat Tan Nguyen et al., submitted for publication). The school health officers were asked to review the website and provide feedback on how useful the website could be for students and for them.

\section{Ethical Considerations}

The study was approved by the Scientific and Training Committee of Can Tho University of Medicine and Pharmacy prior to interviewing at schools. A letter of recommendation from the Can Tho University of Medicine and Pharmacy and a letter of approval from the Department of Education and Training of Can Tho City were presented to the selected schools to ask for permission to interview their health officers. The interviewees were asked for their agreement to participate in the study and gave verbal consent. They were informed that they could refuse to answer any questions or stop the interview at any time without giving any explanation, that all the information would remain confidential, and that neither participation in the study nor refusal to answer questions would affect their employment. The names of the interviewees were not recorded with the data. All recorded interviews and transcribed files were stored on a portable hard drive that stayed with the principle researcher throughout the course of the study.

\section{Results}

\section{Demographic Characteristics of School Health Officers}

The participants included 11 females and four males, with an average age of 38.2 years (range $30-53$ years). They had two to 20 years of working experience in secondary schools. Twelve were general assistant physicians (3-year diploma course at college level). Of those remaining, two were nurses and one was a midwife, each of whom had received a 2-year college diploma.

All respondents noted that the topics of psychology and mental health were not well represented in the curricula used in their training. In addition, during their years of working at schools, the health officers had never had the opportunity for in-service training on psychology or mental health. They did receive short refresher training courses, but the topics were mainly focused on adolescent reproductive health, HIV/ AIDS, food safety, H5N1 influenza, and dengue fever prevention. All of these courses were provided by the Can Tho Department of Education and Training, using trainers from district health centers, health and education media centers, or reproductive health care centers.

As one female assistant doctor with 2 years of working experience said,

"In my 3-year training program, the first 2 years were courses for a general assistant doctor; in the final year we could specialize with a major in internal medicine, pediatrics, or infectious disease. I chose the major in obstetrics and gynecology, and did not learn about mental health".

(School health officer at a private school in Can Tho City).

Another assistant doctor, a male, aged 34, with 9 years of working as a school health officer, reported that,

"About mental health, I did have some training, but with very brief and general information, and very little time."

(School health officer at a public school in Can Tho City).

\section{Common Mental Health Problems of Secondary School Students Encountered by School Health Officers}

Analysis of words and phrases from the 15 interviews established several key themes concerning student mental health. The major themes were stress; depression; suicidal ideation; anger and aggression; sexual orientation; and internet or computer game addition.

The school health officers reported that most of the health problems for which students came to them were minor, such as headache, stomachache, fatigue, hypocalcemia, and among female students, dysmenorrhea. It was also not uncommon that a few students who had no apparent diagnosis went to the school's health room and reported having headache or fatigue. Health officers reported that these students wanted to escape the classroom, sometimes because of stress or anxiety. A female school health officer at a semipublic school reported: 
"Because of stress, pressure or fear of presenting the last lesson in front of the class to the teacher, some students would report headache or fatigue and go to the medical room to ask for medicine while in fact there was no illness when they were checked."

With regard to mental health problems in addition to stress, the respondents reported most commonly seeing students with depression. These students were identified as depressed because they did not want to socialize, study, or play with friends. They wanted to be alone at school and even spoke or thought about suicide.

As mentioned by a female general practitioner, 55 years old, working in a secondary school:

"One child was withdrawn from school for 2 weeks, had signs of psychological instability, she self-harmed and stayed in hospital. I do not know whether she came back home or not. In this case, her mother had moved to live with another man and she lived with her grandmother. Her grandmother had just died, which was a big trauma for her."

One student was reported to have committed suicide at the school, after being scolded by the parents, as reported by a male assistant doctor working for 5 years at a secondary school:

"One student went to the toilet, crying and closed the door. We could not open the door. The student selfharmed and was bleeding, because the family had shouted something about the student's friends, and the student became hopeless and committed suicide."

Another female assistant doctor, 31 years old, a health officer in a secondary school reported:

"One student who graduated last year sometimes became crazy and bit anyone trying to touch the student. That one only wanted people to speak sweetly, if they did not, the student would give them black looks."

Sexual orientation issues were mentioned by several school health officers in different schools; they often referred to "sexual dysfunction" or "gender dysfunction".

A 55-year-old assistant doctor working in a secondary school confirmed that:

"In the case of a male student who likes a male student, if it does not affect their study, the school does not take any action. Female students who like female students are less common than males who like males. Some females have beautiful hair but suddenly cut their hair as a boy's hair style because of wanting to be a boy. Parents of those cases were invited to discuss with a class head teachers."
Another female assistant doctor at a secondary school said about signals of sexual confusion:

"It is also common. Being a girl but she does not like to be a girl, she likes to be a boy."

Another female assistant doctor noted that the students' health problems she encountered at school were "mental disorders and internet addiction."

Considering the causes of mental health problems among their students, the health officers thought that students became stressed through too much work and study, or through too much time spent on other activities, especially computer games. They thought that if the parents put less pressure on the students, and if the students could organize their time better and spend less time on distractions like gaming, they would be able to avoid the development of many mental health problems.

\section{Mental Health Care for Students at the School}

When students come with physical complaints, the health officers give appropriate medicine, such as non-narcotic analgesics. The schools usually offer beds in the medical room for students who need to take short breaks at school, when their complaint is not too serious. In more serious cases, they recommend that the student go home, and contact the parents to take their child.

When students come to them with mental health complaints or symptoms, school health officers try to obtain more information from the student and then to offer appropriate advice. For example, if the student feels isolated and lonely, the officer may contact the teacher to find out more about the situation and behavior of the student in the classroom and to determine whether or not the student is healthy and able to go back to the classroom.

The health officers also reported that Facebook was used as a tool by teachers to monitor student progress. Many students accept the teachers and health officers as friends on their Facebook pages, and schools also have Facebook pages. The health officers check regularly to see what the students post there, especially if they have concerns that the student is not well.

School health officers may also ask a student's friends whether the student participated in social activities and or had any issues related to emotional life or relationships with other students. In some cases, school health officers asked other students, as friends, to help the student with mental health problems. In severe cases, school health officers contacted the parents, explained the situation to them, and advised or asked them to take action. The suggested action could be to reduce pressure and maintain an encouraging atmosphere at home, or to take the student to a hospital for 
a checkup or treatment. It was rare for school health officers to give medications to students for mental health problems.

A 50-year-old primary nurse working at a private school recounted:

"According to me, some students are depressed, not talking, not paying attention to the environment, their faces looking different from the other students. Then I know. I contact that student 1-2 times and if I have free time, I give them advice and encourage them, but I do not say too much."

A male assistant doctor working for 5 years at a secondary school reported that:

"If I find out the reason is love, disagreement, or argument, then I advise them. They are too young to think deeply so I should not put too much pressure on them. It may lead to lethargy and intent to commit suicide." And "For one case of self-harming, I instructed the family to visit a specialised hospital and then to let the student take medicine only."

\section{Recommendations to Improve Mental Health Care in Schools}

The health officers were asked how the mental health care in schools could be improved. They stated that they needed to improve their knowledge of psychology and mental health through continued training. The health officers recognized their need for more mental health training.

They would appreciate additional materials and information to help them identify potential mental health issues; these might be books or websites. It would be important to have the support of the school management board for this work. Furthermore, it could help if a qualified person, such as a physician or psychologist, was invited to talk with school health officers, parents, and students on how to recognize and cope with mental health problems.

"It is better to have a reference document... or a website about mental health care. I will go to read it."

Noted a 29-year-old female assistant doctor working in a specialized secondary school.

Another assistant doctor, a 32-year-old female working at a general secondary school, confirmed that:

"I want more training about psychology and mental health."

\section{Website as a Source of Information}

Five of the 15 health Officers Volunteered to review the website suckhoetre.vn. All of them agreed that the site provided useful mental health information for secondary school students, with diverse content on key topics, and with good graphics and photographs. The fact that the website was created and hosted by Can Tho University of Medicine and Pharmacy helped to build trust for the readers. They recommended improvements to attract more secondary school students: (1) a more colorful design and more user-friendly structure; for example, a 'hot/updated news' section to alert readers to the most current added content; (2) content that is updated weekly or monthly; (3) content that is more agegroup specific; (4) international articles and events with scientific and professional information to make the website more valuable and to distinguish it from other sites. All respondents agreed that the website should be maintained.

Health officers said that they would visit the website more in the future to improve their own knowledge on mental health. They also suggested that the website be advertised via social media, at meetings of parents at schools, and on school announcement boards to get more attention and increase use, not only by students but also by teachers, parents, and the community.

\section{Discussion}

Only fifteen of the 27 local high schools participated in the study, but the level of saturation of the responses obtained suggests that the results may be representative at least for this city. In similar studies in Sweden, saturation was reached after 17 (Larsson, Bjork, Ekebergh, \& Sundler, 2014) or 14 (Jonsson, Maltestam, Bengtsson Tops, \& Garmy, 2017) interviews with school nurses.

School health officers in secondary schools in Can Tho City were mostly trained as assistant doctors, although a few were trained as nurses and one was a midwife. All reported that their basic training was not strong in psychology and mental health, and they had had no continuing education on these topics, leaving them ill-equipped to deal with mental health issues that arose among their students. Their lack of understanding not only hampers their effectiveness, but may also have detrimental effects on the students. Other studies on school mental health revealed that in most Western countries, this work also is done by nurses, who may or may not have specialized training in mental health care for children and adolescents (Haddad, Butler, \& Tylee, 2010; Ravenna \& Cleaver, 2016; Skundberg-Kletthagen \& Moen, 2017). It was also a common finding in other studies, including in the West, that unless the nurses had had specific mental health training, they felt that they were not well prepared to deal with mental health problems and wished to have more training (Bohnenkamp, Stephan, \& Bobo, 2015; SkundbergKletthagen \& Moen, 2017). They also expressed a desire for good screening tools to help with early detection of stress, anxiety, and depression among students, perhaps such as 
those described to be effective for school nurses in the USA (Allison, Nativio, Mitchell, Ren, \& Yuhasz, 2014) and in Sweden (Larsson et al., 2014).

Our findings showed that it was rare for health officers in Can Tho schools to advise students specifically on any kind of medical care regarding all health problems they might need, unless they perceived a case as serious. Then they would refer the student to a hospital or another clinical resource and involve the family in that decision. In many countries, the school nurse is the first person a secondary school student will contact in case of a health problem (Fazel et al., 2014a, b) and in most circumstances, they are able to advise students correctly. In contrast to many Western countries, Vietnam lacks support structures and health workers trained in psychology and psychiatry. This makes it difficult, especially in smaller communities, for the school health officer to know what to recommend to the student and family (Niemi et al., 2010; Vuong et al., 2011). Even in Western countries, school nurses reported that they would be more effective if they had better links to support networks, including social services and youth counseling (Dina \& Pajalic, 2014; Larsson et al., 2014; Moen \& Skundberg-Kletthagen, 2018; Ravenna \& Cleaver, 2016; Skundberg-Kletthagen \& Moen, 2017). This kind of support network is not widely available outside of large cities in Vietnam.

The mental health problems most frequently seen by the school health officers included stress and depression, although there were also a number of reports of students preoccupied with their sexual orientation and a few cases of attempted or successful suicide. These problems are consistent with the information provided by teachers, parents, and students in a previous study in Can Tho (D. T. Nguyen, Dedding, Pham, \& Bunders, 2013). Students with anxiety and depression are at high risk of suicide. Depression is the most powerful predictor of suicide planning, and anxiety and depression are major predictors of suicide (M. T. H. Le, Holton, Kirkman, \& Fisher, 2018; D. T. Nguyen, Dedding, Pham, Wright, et al., 2013). It is therefore especially important for the school health officers to first to identify such cases at an early stage and then to deal with them effectively (Allison et al., 2014). Just as in other countries, there is a need to revise and update the training curricula of health professionals to ensure that health officers can provide care according to the current burden of disease, which would include more attention to mental health.

Prevention of mental health problems was not mentioned by the health officers during the interviews. In an earlier paper from this research team, parents and students were asked about how to reduce mental health problems. Students suggested lectures by psychologists about reducing stress and coping with life, and also recommended a friendlier environment in the schools. The parents focused on the need to reduce gaming and other distractions so that students could focus on their studies (D. T. Nguyen, Dedding, Pham, \& Bunders, 2013).

In the findings of the present study, the school health officers did not recognize and were not confident in dealing with mental health issues among their students because they felt lack of knowledge and experience in that field. In contrast, school nurses in the UK did recognize their role in promoting health and identifying potential problems and addressing them but felt limited by inadequate training and insufficient support from professional networks such as local mental health services (Pryjmachuk, Graham, Haddad, \& Tylee, 2012a, b).

School health officers as well as other stakeholders are influenced by prevailing perceptions of mental health in Vietnamese society. As described by van der Ham et al., a survey and focus group discussions among urban residents of Hue in Central Vietnam found that respondents were not very familiar with mental illness and were unable to name any specific ones (Nguyen Thai \& Nguyen, 2018; van der Ham et al., 2011). They suggested that pressure or stress, and studying or thinking too much were common causes of mental illness. These were mentioned not only by the health officers, but also by parents and teachers in Can Tho (D. T. Nguyen, Dedding, Pham, \& Bunders, 2013; H. T. L. Nguyen, Nakamura, Seino, \& Al-Sobaihi, 2019). The Hue study revealed that perceptions of mental health were influenced by a lack of knowledge and a mix of traditional and modern views. Therefore, more emphasis should be aimed at improving capacity to provide mental health services and on mental health workforce development (Vuong et al., 2011). At present, mental health services lack funding, expertise, facilities, and supportive networks for families and communities (Ng, Than, La, Van Than, \& Van Dieu, 2011). Various interventions, including developing short courses for students, school teachers, and school health officers, may be plausible options to address the situation locally. Making information on mental health issues available through direct or indirect health education communication, including web-based resources may be another option (Nguyen Thai $\&$ Nguyen, 2018). Further studies on the effectiveness of applying web-based resources to disseminate mental health information would help to direct such approaches toward promotion of good mental health and possibly prevention of mental disorders among secondary school students.

As in other countries, school health officers in Vietnam are expected to play an important role in reducing negative health outcomes and risk behaviors among young people. However, according to the current regulations, the role of the school health officer is mainly to organize periodic health examinations, provide first aid and primary health care, inform students about general health issues, ensure school and environmental sanitation, prevent the spread of infectious diseases (including HIV), monitor school safety 
and injury prevention, and ensure food hygiene (Ministry of Education and Training of Vietnam, 2007). There has been little attention from authorities toward mental health. The results of this study and previous studies in Vietnam suggest that the mental health problems of students need to be addressed (D. T. Nguyen, Dedding, Pham, \& Bunders, 2013; D. T. Nguyen, Dedding, Pham, Wright, et al., 2013; Nguyen Thai \& Nguyen, 2018; B. P. Tran, 2007). New regulations are needed to support school health officers to carry out their role in supporting students with mental health problems. The health and education sectors clearly need further insight into the potential key role for school health officers in adolescent mental health care, providing support not only for students but also for teachers and the family (D. T. Nguyen, Dedding, Pham, \& Bunders, 2013; D. T. Nguyen, Dedding, Pham, Wright, et al., 2013).

\section{Strengths and Limitations of the Study}

The qualitative approach with personal interviews gave the researchers access to the ideas and feelings of the respondents. In our study, both male and female officers contributed their experiences, and the respondents were diverse in terms of age range and years of experience. Therefore, our data are likely to be representative of school health officers at least in this city and region, and perhaps much more widely in Vietnam and in countries with a similar school health situation. Future research should involve experts in adolescent mental health who could identify in greater detail the gaps and needs for training among the school health officers.

\section{Summary and Conclusions}

In general, the challenges faced by school health officers in Can Tho City, Vietnam, appeared to be similar in many ways to those reported by school nurses in Western countries, in that they had specialized training in health care for children and adolescents but not in mental health care, and they often felt ill-equipped by training and experience to do a good job of managing mental health problems among high school students. The situation in Vietnam is more difficult due to the lack support from social service organizations and other support systems for adolescents that nurses in many wealthier countries can reach out to for assistance. In addition, not enough attention has been paid in Vietnam toward training the officers, and providing adequate support within and outside the schools for such a role. Policies and strategies for training and refresher courses for school health officers to equip them with the knowledge and skills they need to support students from grades six to 12 with mental health problems should have high priority at all levels. Continued investment in the workforce and structures for better social and psychological support are also needed.

Acknowledgements We acknowledge the financial support of the "Strengthening teaching and research capacity of preventive medicine staffs to meet the challenges of emerging infections and new environmental hazards to health" Project from the Dutch Organisation for International Cooperation, Dutch Organisation for Internationalisation in Education (NUFFIC) and the Dutch government. We also thank the Coordinator Board for the project at Hanoi Medical University, Hanoi, Vietnam. We would like to express our special thanks to the school health officers who gave their time to participate in this study.

Author Contributions All authors contributed to the study conception and design. Material preparation, data collection, and analysis were performed by DTN, EPW, TTP, and JB. The first draft of the manuscript was written by DTN, and all authors commented on earlier versions of the manuscript. All authors read and approved the final manuscript.

\section{Compliance with Ethical Standards}

Conflict of interest The authors declare that they have no competing interests.

Open Access This article is licensed under a Creative Commons Attribution 4.0 International License, which permits use, sharing, adaptation, distribution and reproduction in any medium or format, as long as you give appropriate credit to the original author(s) and the source, provide a link to the Creative Commons licence, and indicate if changes were made. The images or other third party material in this article are included in the article's Creative Commons licence, unless indicated otherwise in a credit line to the material. If material is not included in the article's Creative Commons licence and your intended use is not permitted by statutory regulation or exceeds the permitted use, you will need to obtain permission directly from the copyright holder. To view a copy of this licence, visit http://creativecommons.org/licenses/by/4.0/.

\section{Appendix: Guideline for In-Depth Interview School Health Workers}

\section{Objectives}

1. To identify common mental health problems among secondary school students encountered by school health staff in secondary schools in Can Tho City, Vietnam.

2. To describe the activities of school health workers related to mental health care for the students.

3. To identify potential approaches and activities to improve care in mental health at secondary schools.

\section{Contents}

\section{Background information}

1. How long have you worked in school health? How long at this school? (Check about times the staff is avail- 
able and where the office is, if it is easy for students to access? Also check on confidentiality-is it private enough for students to feel comfortable to see the health staff).

2. How old are you?

3. What is your specialized training for providing health care in the school?

4. Did you receive any specialized training in youth development?

5. Did you receive any specialized training in mental health?

\section{Mental health problems and health care activities for mental health problem at school}

6. What health problems do you often encounter among the students?

7. What do you do to deal with these problems? (For example: treat, refer to other medical facility? If so which one, is there a relation with one particular clinic or hospital?)

8. Do you meet mental health problems among the students at school?

9. How do you recognize mental health problems?

10. What advice do you give to students with mental health problems?

11. Do you think that students with mental health problems find it convenient or easy to come to you with their problems? If not, where do you think they would look for information or assistance?

12. Is the family involved in solving the mental health problems? What activities of the family could help solve mental health problems for students?

13. Are teachers involved in solving the mental health problems? What activities of teachers could help to solve mental health problems for students?

14. Are other students involved in solving the mental health problems? What activities of other students could help to solve mental health problems for affected students?

\section{Suggestions for Improved Mental Health Care at Secondary Schools}

(Now we are interested in ideas about how to improve mental health care for students in schools. Please answer the following additional questions:

15. According to your idea, what activities could you yourself do to improve the provision of mental health care for students?
16. If you would need additional training, what topics would help you to improve the provision of mental health care for students?

17. Who else should be involved in providing mental health care for students?

18. What kinds of support do you need to provide better mental health care for the students?

19. What support do the schools need to provide better care for the students?

20. Anything other suggestions or comments?

\section{References}

Allison, V. L., Nativio, D. G., Mitchell, A. M., Ren, D., \& Yuhasz, J. (2014). Identifying symptoms of depression and anxiety in students in the school setting. The Journal of School Nursing, 30(3), 165-172. https://doi.org/10.1177/1059840513500076.

Arenson, M., Hudson, P. J., Lee, N., \& Lai, B. (2019). The evidence on school-based health centers: A review. Global Pediatric Health, 6, 1. https://doi.org/10.1177/2333794x19828745.

Bohnenkamp, J. H., Stephan, S. H., \& Bobo, N. (2015). Supporting student mental health: The role of the school nurse in coordinated school mental health care. Psychology in the School, 52(7), 714-727.

Communist Party of Vietnam. (2017). No. 20-NQ/TW: Resolution of the sixth plenary session the 12th Party Central Committee on the protection, care and improvement of people's health in the new situation. Retrieved March 29, 2019, from http://unaid s.org.vn/wp-content/uploads/2017/12/RESOLUTION.-En.pdf.

Daya, P. A., \& Karthikeyan, G. (2018). Depression, anxiety, stress and its correlates among urban school going adolescents in Tamilnadu, India. International Journal of Research in Medical Sciences, 6(8), 2813-2817.

Dina, F., \& Pajalic, Z. (2014). How school nurses experience their work with schoolchildren who have mental illness-A qualitative study in a Swedish context. Global Journal of Health Science, 6(4), 1-8. https://doi.org/10.5539/gjhs.v6n4p1.

Do, M., Pham, N. N., Wallick, S., \& Nastasi, B. K. (2014). Perceptions of mental illness and related stigma among Vietnamese populations: findings from a mixed method study. Journal of Immigrant and Minority Health, 16(6), 1294-1298. https://doi. org/10.1007/s10903-014-0018-7.

Fazel, M., Hoagwood, U., Stephan, U., \& Ford, T. (2014a). Mental health interventions in schools 1: Mental health interventions in schools in high-income countries. The Lancet Psychiatry, 1(5), 377-387. https://doi.org/10.1016/S2215-0366(14)70312-8.

Fazel, M., Patel, V., Thomas, S., \& Tol, W. (2014b). Mental health interventions in schools 2: Mental health interventions in schools in low-income and middle-income countries. Lancet Psychiatry, 1, 388-398. https://doi.org/10.1016/S2215 -0366(14)70312-8.

Garmy, P., Berg, A., \& Clausson, E. K. (2015). A qualitative study exploring adolescents' experiences with a school-based mental health program. BMC Public Health, 15, 1074. https://doi. org/10.1186/s12889-015-2368-z.

Greytak, E., Torres-Guillén, S., Morton, M., Jordan, H., Coyle, S., Mann, A., \& Sun, W.-L. (2019). Cops and no counselors: How the lack of school mental health staff is harming students. https ://www.aclu.org/sites/default/files/field_document/030419-aclus chooldisciplinereport.pdf. 
Haddad, M., Butler, G. S., \& Tylee, A. (2010). School nurses' involvement, attitudes and training needs for mental health work: A UKwide cross-sectional study. Journal of Advanced Nursing, 66(11), 2471-2480. https://doi.org/10.1111/j.1365-2648.2010.05432.x.

Harpham, T., \& Tran, T. (2006). From research evidence to policy: Mental health care in Vietnam. Bulletin of the World Health Organization, 84(8), 664-668.

Hong, M. (2008). Mentally ill patients face discrimination. Retrieved June 22, 2020, from https://vietnamnews.vn/society/healt h/181201/mentally-ill-patients-face-discrimination.html.

Jonsson, J., Maltestam, M., Bengtsson Tops, A., \& Garmy, P. (2017). School nurses' experiences working with students with mental health problems: A qualitative study. The Journal of School Nursing. https://doi.org/10.1177/1059840517744019.

Kumar, K. S., \& Akoijam, B. S. (2017). Depression, anxiety and stress among higher secondary school students of Imphal, Manipur. Indian Journal of Community Medicine, 42(2), 94-96. https://doi.org/10.4103/ijcm.IJCM_266_15.

Larsson, M., Bjork, M., Ekebergh, M., \& Sundler, A. J. (2014). Striving to make a positive difference: School nurses' experiences of promoting the health and well-being of adolescent girls. The Journal of School Nursing, 30(5), 358-365. https://doi.org/10.1177/10598 40513505223.

Le, M. T. H., Holton, S., Kirkman, M., \& Fisher, J. (2018). "I feel that life is meaningless": Vietnamese adolescents' experiences of and reflections about interpersonal violence. Global Mental Health (Camb), 5, e12. https://doi.org/10.1017/gmh.2017.34.

Le, M. T., Holton, S., Nguyen, H. T., Wolfe, R., \& Fisher, J. (2016). Poly-victimisation and health risk behaviours, symptoms of mental health problems and suicidal thoughts and plans among adolescents in Vietnam. International Journal of Mental Health Systems, 10, 66. https://doi.org/10.1186/s13033-016-0099-x.

Ministry of Education and Training of Vietnam. (2007). Decision 73/2007/QĐ-BGDĐT: Decision on promulgating regulations on medical activities in primary schools, junior secondary schools, senior secondary schools and multi-lvel secondary schools (Quyết định ban hành qui định về hoạt động y tế trong các trường tiểu hoc, trường trung hoc co sở, trường trung hoc phổ thông và trường phổ thông có nhiều cấp học). Retrieved August 12, 2017, from https://thuvienphapluat.vn/van-ban/Giao-duc/Quyet-dinh73-2007-QD-BGDDT-Quy-dinh-hoat-dong-y-te-truong-tieu-hoctrung-hoc-co-so-pho-thong-60656.aspx.

Ministry of Health and Ministry of Education and Training. (2016). Joint Circular No. 13/2016/TTLT-BYT-BGDDT dated May 12, 2016, regulations on healthcare activities in schools. Retrieved March 11, 2019, from https://vanbanphapluat.co/joint-circular-132016-ttlt-byt-bgddt-regulations-healthcare-activities-in-schools.

Moen, Ø. L., \& Skundberg-Kletthagen, H. (2018). Public health nurses' experience, involvement and attitude concerning mental health issues in a school setting. Nordic Journal of Nursing Research, 38(2), 61-67. https://doi.org/10.1177/2057158517711680.

Ng, C. H., Than, P. T., La, C. D., Van Than, Q., \& Van Dieu, C. (2011). The national community mental health care project in Vietnam: A review for future guidance. Australas Psychiatry, 19(2), 143-150. https://doi.org/10.3109/10398562.2011.563308.

Nguyen, X. C. (2012). Mental health a Vietnamese perspective. Retrieved 22 June, 2020, from https://www.vmhs.org.uk/media /17739/mental-health-vietnamese-perspective.pdf.

Nguyen, D. T., Dedding, C., Pham, T. T., \& Bunders, J. (2013a). Perspectives of pupils, parents, and teachers on mental health problems among Vietnamese secondary school pupils. BMC Public Health, 13, 1046. https://doi.org/10.1186/1471-2458-13-1046.

Nguyen, D. T., Dedding, C., Pham, T. T., Wright, P., \& Bunders, J. (2013b). Depression, anxiety, and suicidal ideation among Vietnamese secondary school students and proposed solutions: A cross-sectional study. BMC Public Health, 13, 1195. https://doi. org/10.1186/1471-2458-13-1195.

Nguyen, T. H., Dunne, M. P., \& Le, V. A. (2010). Multiple-type child maltreatment and adolescent mental health in Vietnam. Bulletin of the World Health Organization, 88(1), 22-30.

Nguyen, H. T. L., Nakamura, K., Seino, K., \& Al-Sobaihi, S. (2019). Impact of parent-adolescent bonding on school bullying and mental health in Vietnamese cultural setting: Evidence from the global school-based health survey. BMC Psychol, 7(1), 16. https://doi. org/10.1186/s40359-019-0294-z.

Nguyen Thai, Q. C., \& Nguyen, T. H. (2018). Mental health literacy: Knowledge of depression among undergraduate students in Hanoi, Vietnam. International Journal of Mental Health Systems, 12, 19. https://doi.org/10.1186/s13033-018-0195-1.

Niemi, M., Thanh, H. T., Tuan, T., \& Falkenberg, T. (2010). Mental health priorities in Vietnam: A mixed-methods analysis. BMC Health Services Research, 10, 257. https://doi. org/10.1186/1472-6963-10-257.

Overseas Development Institute and UNICEF Vietnam. (2018). Mental health and psychosocial wellbeing among children and young people in selected provinces and cities in Viet Nam. Retrieved December 30, 2019, from https://www.unicef.org/vietnam/media /976/file/Study\%20on\%20mental\%20health\%20and\%20psychoso cial\%20wellbeing $\% 20$ of $\% 20$ Children $\% 20$ and $\% 20$ Young $\% 20$ peo ple\%20in\%20Viet\%20Nam.pdf.

Paschall, M. J., \& Bersamin, M. (2018). School-based health centers, depression, and suicide risk among adolescents. American Journal of Preventive Medicine, 54(1), 44-50. https://doi.org/10.1016/j. amepre.2017.08.022.

Prime Minister of Vietnam. (2006). Directive 23/2006/CT-TTg: Directive on strengthening health care at school (Chỉ thị về việc tăng cường công tác y tế trong các trường học). Retrieved August 12, 2017, from https://thuvienphapluat.vn/van-ban/Giao-duc/ Chi-thi-23-2006-CT-TTg-tang-cuong-cong-tac-y-te-truong-hoc13022.aspx.

Prime Minister of Vietnam. (2009). Decision 401/QĐ-TTg: Decision on approving the program on prevention and control of diseases in educational institutions belonging to the public education system (Quyết định về việc phê duyệt chương trình phòng, chống bệnh, tật trong các cơ sở giáo dục thuộc hệ thống giáo dục quốc dân). Retrieved August 12, 2017, from https://thuvienphapluat.vn/vanban/Giao-duc/Quyet-dinh-401-QD-TTg-phe-duyet-chuong-trinh -phong-chong-benh-tat-trong-cac-co-so-giao-duc-thuoc-he-thong -giao-duc-quoc-dan-86772.aspx.

Pryjmachuk, S., Graham, T., Haddad, M., \& Tylee, A. (2012). School nurses' perspectives on managing mental health problems in children and young people. Journal of Clinical Nursing, 21(5-6), 850-859. https://doi.org/10.1111/j.1365-2702.2011.03838.x.

Ravenna, J., \& Cleaver, K. (2016). School nurses' experiences of managing young people with mental health problems: A scoping review. The Journal of School Nursing, 32(1), 58-70. https://doi. org/10.1177/1059840515620281.

Rosvall, P. A., \& Nilsson, S. (2016). Gender-based generalisations in school nurses' appraisals of and interventions addressing students' mental health. BMC Health Services Research, 16, 451. https:// doi.org/10.1186/s12913-016-1710-1.

Skundberg-Kletthagen, H., \& Moen, O. L. (2017). Mental health work in school health services and school nurses' involvement and attitudes, in a Norwegian context. Journal of Clinical Nursing, 26(23-24), 5044-5051. https://doi.org/10.1111/jocn.14004.

Tran, B. P. (2007). Improving Knowledge of factors that influence the mental health of school children in Vietnam. Thesis for the Master of Public Health. Thesis for the Master of Public Health. Queensland University of Technology. Brisbane. 
Tran, Q. A., Dunne, M. P., Vo, T. V., \& Luu, N. H. (2015). Adverse childhood experiences and the health of university students in eight provinces of Vietnam. Asia-Pacific Journal of Public Health, 27(8 Suppl), 26S-32S. https://doi.org/10.1177/101053951558981 2.

van der Ham, L., Wright, P., Van, T. V., Doan, V. D., \& Broerse, J. E. (2011). Perceptions of mental health and help-seeking behavior in an urban community in Vietnam: An explorative study. Community Mental Health Journal, 47(5), 574-582. https://doi. org/10.1007/s10597-011-9393-x.

Vuong, D. A., Van Ginneken, E., Morris, J., Ha, S. T., \& Busse, R. (2011). Mental health in Vietnam: Burden of disease and availability of services. Asian Journal of Psychiatry, 4(1), 65-70. https ://doi.org/10.1016/j.ajp.2011.01.005.

Werner-Seidler, A., Perry, Y., Calear, A. L., Newby, J. M., \& Christensen, H. (2017). School-based depression and anxiety prevention programs for young people: A systematic review and meta-analysis. Clinical Psychology Review, 51, 30-47. https://doi. org/10.1016/j.cpr.2016.10.005.

World Health Organization. (2012). Depression: A global crisis World Mental Health Day, October 102012.

World Health Organization. (2018). Adolescents and mental health. Retrieved March 28, 2019, from https://www.who.int/news-room/ fact-sheets/detail/adolescent-mental-health.

Publisher's Note Springer Nature remains neutral with regard to jurisdictional claims in published maps and institutional affiliations. 